\title{
OS SINAIS DOS SURDOS: UMA ANÁLISE A PARTIR DE UMA PERSPECTIVA CULTURAL
}

\section{THE DEAF'S SIGNS: AN ANALYSIS THROUGH CULTURAL PERSPECTIVE}

\author{
Isabelle Lima Souza* \\ Ana Luisa Gediel ${ }^{* *}$
}

\section{RESUMO}

O presente trabalho descreve a constituição dos sinais próprios e o processo de nomeação das pessoas Surdas, levando em conta a Fonologia, aliada a questões consideradas relevantes culturalmente na comunidade de fala estudada. Realizamos uma pesquisa etnográfica com pessoas Surdas, em uma cidade da Zona da Mata Mineira, para o mapeamento dos sinais próprios e a verificação de suas principais características fonológicas. Como instrumentos de coleta e análise de dados, utilizamos caderno de notas, diário de campo e câmera. A etnografia possibilitou uma maior compreensão acerca dos demarcadores culturais imersos nesse processo, tendo em vista a perspectiva dos Surdos considerados líderes, os quais elaboram os sinais próprios. Como resultados da pesquisa, percebemos uma aproximação da inserção de aspectos fonológicos de acordo com a referência de elementos culturais ligados à iconicidade e à arbitrariedade de cada sinal. Ainda, foram identificados e mapeados um conjunto de sinais a partir de alguns dos parâmetros fonológicos da Libras que remetem às seguintes constatações: 1) padronizações que podem ser consideradas categorização de gênero; 2) empréstimo linguístico da Língua Portuguesa para a Libras, que ocorreu por meio do alfabeto datilológico, pois, muitas vezes, a Configuração de Mão (CM) dos sinais faz referência ao nome próprio das pessoas; e 3) iconicidade e arbitrariedade dos sinais no processo de nomeação.

Palavras-chave: Libras, sinais próprios, parâmetros gramaticais, contexto cultural Surdo.

\section{ABSTRACT}

This paper describes the establishment of own signs and how it is the process to give a sign for Deaf people, considering phonological and cultural approach as relevant issues in speech community studied. We conducted an ethnographic research with Deaf people, in a city at Zona da Mata Mineira, to map signs and verify the main phonological characteristics. We used notes, diary and camera to collect data and develop the analysis. The ethnography enabled to understand the cultural paths immersed in this process, given the perspective of the Deaf considered leaders who draw up own signs for Deaf people. As results of the research, we realized that the phonological aspects are linked to the reference of cultural elements which bring understanding for iconicity and arbitrariness of each signal. We have

\footnotetext{
* Universidade Federal de Viçosa, Viçosa, MG. Brasil. isabelle.araujolima@gmail.com

** Universidade Federal de Viçosa, Viçosa, MG. Brasil. ana.gedielufv@gmail.com
} 
been identified and mapped to a set of signs from some of the parameters of phonological aspects in Libras. These refer to the following conclusions: 1) standardization that can be considered as categorization of gender, 2) linguistic loan from Portuguese to Libras, which happened through the fingerspelling alphabet, because, many times, the Hand Configuration (HC) of signs are related to people's own names; and 3) iconicity and arbitrariness of the signs in the nomination process.

Keywords: Libras, own signs, grammatical parameters, Deaf cultural context.

\section{INTRODUÇÃO}

O processo de nomeação por meio de sinais que representam os nomes próprios das pessoas Surdas ${ }^{1}$ que utilizam a Língua de Sinais como principal forma de comunicação é um fenômeno social recorrente em diversos grupos de sinalizantes (NONAKA et al, 2015; HEREDIA, 2007). Após o recebimento do sinal próprio, a pessoa passa a se identificar e a ser reconhecida a partir de tal sinal. Neste estudo, descrevemos algumas das nuances presentes no processo de nomeação, as quais condizem com a recorrência do uso de especificidades gramaticais.

Para discutir tal abordagem, usufruímos da interdisciplinaridade da Linguística Aplicada² (LA), a qual tem por objeto de estudo a língua e a linguagem em seus diversos contextos sociais de uso, o que viabiliza o diálogo teóricometodológico com a Antropologia Linguística.

A Antropologia Linguística tem como pressuposto teórico a relação entre a linguagem em uso e a cultura (DURANTI, 2001). Compreendemos que a língua, além de estar imersa enquanto fator cultural, também se constitui como ação social. É através dela que as pessoas criam, compartilham significados e ressignificam as suas ações. Dessa maneira, torna-se propício aprender os aspectos culturais do Surdo, pois, assim, compreendemos os diferentes usos da Língua Brasileira de Sinais (Libras). O estabelecimento dessa relação auxilia na discussão de como ocorre o processo de nomeação e quais são as especificidades gramaticais

1 O termo comunidade Surda é considerado êmico e a palavra "Surda", com a letra S em maiúscula, ocorre para a denominação daquelas pessoas que se consideram culturalmente diferentes e que utilizam a LIBRAS como primeira língua (PADDEN, HUMPHRIES, 2006).

2 Vale salientar que o histórico de formação da Linguística Aplicada (LA) advém da interligação de teorias e procedimentos metodológicos advindos da Linguística, da Antropologia, da Sociologia e da Educação, a fim de se aplicarem as teorias à prática pedagógica, configurando-se, desde a sua origem, como um campo interdisciplinar. Com o decorrer dos anos, a LA passou por um processo de redefinição teórica e epistemológica. Atualmente, configura-se como uma área autônoma e com o objeto de estudo língua/linguagem em seus diversos contextos sociais de uso (MENEZES; SILVA; GOMES, 2009). 
estabelecidas e compartilhadas entre pessoas Surdas, em um município da Zona da Mata Mineira, a partir da perspectiva daqueles que nomeiam.

Dentre os diversos símbolos e significados compartilhados entre as pessoas Surdas que utilizam a Libras como principal meio de comunicação e de expressão, os sinais que se referem aos nomes próprios são considerados um registo de entrada na comunidade Surda (GEDIEL, 2010). A presente pesquisa busca discutir as questões evidenciadas a partir do processo de nomeação das pessoas Surdas, com os objetivos de identificar, mapear e descrever os aspectos fonológicos dos sinais, os quais estão relacionados com o background cultural de cada um dos sujeitos que nomeiam.

Diante das evidências etnográficas levantadas, a partir de uma abordagem qualitativa, percebemos que a iconicidade ou arbitrariedade de cada sinal próprio é um elemento significativo da cultura. A subjetividade dos indivíduos que nomeiam influencia na busca de elementos fonológicos apropriados à pessoa que receberá o sinal, de acordo com a observação das principais características físicas da pessoa a ser nomeada, como o formato do cabelo e/ou do rosto, marcas faciais visíveis e/ou expressões marcantes. Desse modo, a percepção das pessoas Surdas que nomeiam em Libras faz com que os sinais sejam elaborados de uma forma que se aproximem à identificação da pessoa, tornando-se essa identificação o sinal próprio em Língua de Sinais.

Heredia (2007) descreve que receber um sinal próprio é como ganhar uma identidade perante aquela comunidade. De modo geral, os sinais próprios referem-se às características físicas, mas também podem fazer alusão ao trabalho desempenhado pela pessoa. A autora afirma que o sinal confere um status linguístico e um sentimento de pertencimento à comunidade Surda. Notamos, assim, uma correspondência entre a dinâmica social das comunidades Surdas e o modo como elas se expressam linguisticamente.

Para trazermos os pressupostos que embasam o desenvolvimento da pesquisa, apresentamos uma breve descrição das questões linguísticas da Libras que dialogam com os fenômenos sociais e culturais. Em seguida, contextualizamos a perspectiva metodológica da pesquisa, evidenciando as especificidades do grupo estudado etnograficamente e os métodos e técnicas de coleta de dados. Logo em seguida, descrevemos os elementos reconhecidos pelos Surdos líderes como significativos para o processo de nomeação, uma discussão e uma análise do processo de nomeação das pessoas Surdas, envolvendo as principais características gramaticais impressas nos sinais próprios. Por fim, trazemos algumas considerações sobre as contribuições da pesquisa e as especificidades fonológicas dos sinais próprios como marcadores culturais da Libras. 


\section{A LIBRAS E A CULTURA SURDA}

A língua é destacada como um aspecto essencial da cultura, meio pelo qual os indivíduos processam suas referências de mundo (DURANTI, 2001). Segundo o autor, a forma como as palavras são mobilizadas nas ações performáticas e na fala em interação trazem um conjunto de sentidos que possibilitam uma análise da realidade social. Ao levarmos em consideração a complexidade linguística da Libras e entendermos que é um importante fator cultural, podemos afirmar que essa língua é uma forma de representação do mundo social utilizada no processo de interação entre os indivíduos, que reproduz questões sociais imbricadas em nosso cotidiano, como, por exemplo, na constituição de sinais para os nomes próprios.

Essa língua é reconhecida como uma língua natural Surda, por possuir uma composição linguística própria, conformando características eminentes das línguas espaciais-visuais (GESSER, 2009). Nos anos 1960, Stokoe dedicou-se à gramática da Língua de Sinais Americana - ASL e desmistificou uma série de crenças a respeito da universalidade da Língua de Sinais, sua naturalidade linguística, a complexidade gramatical, além de apontar para as variações de acordo com a cultura de cada população (QUADROS E KARNOPP, 2004).

A gramática das Línguas de Sinais emerge a partir da forma como os Surdos entendem o universo simbólico em que estão inseridos, significando-o de acordo com os códigos de uma Língua espacial visual. Desse modo, entendemos que os sinais não são somente um fator de extrema importância para a comunicação, mas para a compreensão de mundo desses sujeitos e das formas como se identificam e são identificados.

Os sinais são formados e orientados gramaticalmente a partir dos cinco parâmetros, também conhecidos como unidades mínimas na Libras. De acordo com os estudos de Quadros e Karnopp (2004), a fonologia dos sinais é constituída pelo uso da Configuração de Mão (CM), da Locação (L), do Movimento (M), da Expressão Não Manual (ENM) e da Orientação de Mão (Or). As combinações dessas unidades mínimas são utilizadas tanto na elaboração dos sinais próprios como na construção dos demais sinais nessa língua.

A fonologia da Libras é, então, estabelecida a partir desses cinco parâmetros que produzem os sinais e que têm um lugar específico no corpo para sua realização, isto é, na parte superior, ocupando o espaço da cintura até a cabeça (GEDIEL, 2010). Esse mesmo padrão fonológico é encontrado nos sinais próprios das pessoas sinalizantes. ${ }^{3}$

\footnotetext{
3 A fim de evitarmos uma concepção audiocêntrica das Línguas de Sinais, optamos por chamar de sinalizante e de visualizador a pessoa que utiliza a LIBRAS para se comunicar: o sinalizante é aquele que produz o discurso, e o visualizador, a pessoa a quem o discurso está sendo endereçado.
} 


\subsection{Relação entre os sinais próprios, a comunidade de fala e a fonologia}

Consideramos os sinais próprios um dos aspectos conectados às questões linguísticas que as pessoas Surdas sinalizantes compartilham, tendo em vista o contexto social e cultural em que estão imersas.

Os sinais próprios são considerados um elemento importante da cultura Surda, pois, a partir do momento em que a pessoa é batizada por um Surdo que está há mais tempo na comunidade, ela passa a receber uma identidade Surda, sendo considerada uma pessoa "de dentro" da comunidade (HEREDIA, 2007). Assim, o ritual de batismo representaria uma ruptura simbólica, correspondendo a um ritual de passagem ${ }^{4}$, pelo qual o sujeito deixa de ser deficiente auditivo para se tornar Surdo. Dessa maneira, a nominação das pessoas Surdas envolve aspectos simbólicos que fazem parte no universo desses sujeitos.

De acordo com Gumperz e Cook-Gumperz (1982), ao levarmos em consideração a identidade social de uma comunidade de fala, podemos perceber as divergências linguísticas apenas pelo entendimento do percurso e das especificidades históricas dos usuários da língua. Em consonância com esse processo, os sinais próprios também estão relacionados às mudanças sociais e à forma como estas são impressas nas práticas comunicativas, e os autores refletem sobre as normas de linguagem a partir de uma perspectiva sociocultural. Assim, as normas estão de acordo com a realidade social, com os símbolos demarcadores da identidade de grupo e com as convenções comunicativas estabelecidas por ele.

A perspectiva de comunidade de fala também é utilizada por Nonaka (2014) para descrever e analisar as características e funções compartilhadas por meio da Língua de Sinais, em uma comunidade de Surdos e ouvintes na Tailândia. A partir da etnografia realizada entre os membros da comunidade, Nonaka (2014) descreveu questões econômicas, políticas e culturais para a manutenção das relações sociais, as quais foram analisadas levando em consideração as particularidades linguísticas.

A partir dessa perspectiva, podemos compreender os Surdos sinalizantes em um município da Zona da Mata Mineira (MG) como uma comunidade de fala, na medida em que compartilham as especificidades históricas, as divergências e as mudanças sociais presentes na língua. Assim, os sinais próprios são significados compartilhados entre os membros e estão sujeitos a mudanças sociais, históricas e culturais percebidas tanto nos aspectos estruturais dos sinais quanto na maneira como os sujeitos se relacionam por meio deles.

O estudo dos nomes próprios, denominado onomástica, é significativo para compreendermos os aspectos socioculturais de uma determinada população -

4 Referimo-nos ao processo ritual descrito por Victor Turner (1986). 
como afirma Carvalhinhos (2007), ao estudar os nomes próprios dos brasileiros. Nas palavras do autor:

O nome de uma pessoa (...) é um manancial rico para conhecimento não apenas da língua, mas também permite apreender um pouco da cultura, religião e até mesmo a ideologia de um povo em determinada época, uma vez que a língua mantém intactos nos nomes das pessoas as partículas mínimas de significação (semas) (CARVALHINHOS, 2007, p. 17).

Embora Carvalhinho (2007) esteja se referindo à Língua Portuguesa, a qual representa a modalidade oral auditiva, percebemos que, nas Línguas de Sinais, ocorre o mesmo fenômeno. Notamos semelhança com a nomeação em Libras, uma vez que os sinais próprios se vinculam aos aspectos sociais e culturais envolvidos no processo. Assim, as partículas mínimas nos remetem às características sociais, aos papéis de gênero e à significação cultural, que é representada por meio da iconicidade do sinal e do background cultural dos sujeitos que nominam.

É importante ressaltar que a iconicidade varia de acordo com a cultura não há um padrão universal, uma vez que as representações visuais são criadas, significadas e compartilhadas pelos sujeitos (PIZZUTO; VOLTERRA, 2000, ORTEGA; MORGAN, 2015). O mesmo ocorre com os sinais próprios, pois, quando tratamos da iconicidade na fonologia dos sinais, estamos partindo do que é icônico para o sinalizante e para o visualizador. Logo, para compreendermos a significação dos sinais próprios pelos Surdos sinalizantes participantes da pesquisa, temos de compreender a relação entre os parâmetros gramaticais dos sinais e os aspectos microssociais envolvidos. ${ }^{5}$

No que diz respeito à Fonologia dos sinais próprios, Nonaka et al (2015) demonstram como a Fonologia dos sinais próprios da Língua de Sinais Japonesa se relaciona com o contexto cultural do Japão. Segundo as autoras, a maioria dos sinais próprios são formados tendo como base a escrita dos caracteres japoneses e a pronúncia dos caracteres Kanji dos sobrenomes. Esse padrão associado aos sobrenomes reflete a ênfase nos costumes da cultura japonesa a serem conservados. Além disso, é possível vincular o sistema onomástico da Língua de Sinais Japonesa à experiência social dos Surdos japoneses e ao estabelecimento da educação formal dos Surdos dentro dessa cultura.

Nas escolas modernas, os nomes e os sobrenomes das famílias eram enfatizados nas lições, pois os nomes no Japão tinham um significado político, religioso e social, servindo como identificadores, conferindo-lhes sinais de pertencimento social e

5 Neste artigo, utilizamos Pizzuto e Volterra (2000) e Ortega e Morgan (2015) como base para a definição de arbitrariedade e iconicidade na Libras. 
político. Da mesma maneira, as autoras citam as escolas para Surdos, as quais eram administradas por ouvintes, e nas quais os Surdos deveriam aprender a pronúncia e a escrita de seus sobrenomes, influenciando, assim, a Morfologia e as características fonéticas dos sinais representados através dos caracteres Kanji (NONAKA ET AL, 2015).

Notamos que os sinais próprios são um fenômeno presente na maioria das culturas sinalizantes, os quais correspondem à forma como a pessoa se identifica e é identificada por outras pessoas sinalizantes. Entretanto, a composição do sinal e o processo de elaboração da nomeação, que condizem com significados atribuídos aos sinais próprios, variam de cultura para cultura.

Considerando isso, ressaltamos aqui dois aspectos do processo de nomeação dos Surdos sinalizantes da Libras em um Município da Zona da Mata Mineira: 1) o processo de nomeação assemelha-se a um ritual de batismo, momento no qual a pessoa passa a ser reconhecida como alguém inserido no meio Surdo - quando recebe um sinal já não mais é identificada entre os sinalizantes pelo seu nome em português, mas, sim, por seu sinal próprio; 2) o sinal próprio possui um status identitário, visto que é individual e particular de cada sujeito, distinguindo-o no meio de outros. Os sinais próprios são um artefato de distinção não apenas pela sua composição fonológica, mas pela sua função. Tais questões serão demonstradas e discutidas na seção 4 .

\section{PERCURSO METODOLÓGICO}

Nesta seção, discorremos acerca dos procedimentos metodológicos da pesquisa e do processo de coleta e análise de dados. Para desenvolvermos a pesquisa sobre os sinais próprios, utilizamos uma base qualitativa, uma vez que tratamos de questões relativas à subjetividade dos indivíduos (MINAYO, 1994).

Adotamos a etnografia como metodologia de pesquisa, pois, para fazermos o mapeamento das pessoas que nomeiam em Línguas de Sinais e a demarcação dos sinais próprios do contexto investigado, foi necessário compreendermos os aspectos culturais dos Surdos. E isso se torna possível por meio da convivência com esses sujeitos, tendo em vista que, na observação participante, o pesquisador procura traduzir determinados aspectos simbólicos da cultura observada, atentando a todos os elementos que imprimem sentidos (DURANTI, 1997).

O método etnográfico, devido à sua particularidade, permite o registro de contextos de cultura, considerando-se a percepção das especificidades do grupo 
estudado. Desse modo, durante o período das idas a campo, que ocorreu durante os anos de 2013 e 2014, deu-se atenção à experiência social e ao estabelecimento das relações vivenciadas junto às pessoas Surdas de uma cidade da Zona da Mata Mineira. Laplantine (2003) afirma que o pesquisador deve observar todos os elementos que imprimem sentidos, tais como a visão, o olhar, a memória e o imaginário, bem como as formas como esses sentidos são traduzidos no campo da linguagem por aqueles que vivenciam a cultura.

Por meio do método etnográfico, é possível que o pesquisador analise determinados eventos, grupos, situações sociais, processos rituais ou qualquer outra prática cultural vinculada à língua. Sendo assim, as diferentes relações sociais que perpassam a constituição linguística do grupo se entrelaçam como temas interdisciplinares e as nomeações próprias adentram como um elemento específico da Libras e da cultura Surda.

Como instrumentos de coleta de dados, utilizamos a observação participante, o caderno de notas e os diários de campo, além da realização de entrevistas semiestruturadas. O foco da etnografia deteve-se em três líderes: são considerados pelos demais sinalizantes da cidade como aqueles que "conhecem muita gente" e que "gostam de ensinar a Libras". Por isso, categorizamo-los como Surdos líderes. ${ }^{7}$ Além disso, foi perceptível a influência de liderança à frente de atividades envolvendo a Libras, assim como a legitimação para a nomeação das pessoas com os sinais próprios.

Essa fase de observação do comportamento do grupo foi uma etapa primordial para a pesquisa, pois a língua está relacionada com os aspectos sociais e culturais de determinado grupo. Logo, para compreender o significado das ações sociais e o que os indivíduos de uma determinada cultura falam enquanto desempenham certa atividade interacional, é preciso compreender os aspectos sociais e culturais da língua em questão.

Malinowski (1978) já falava dessas questões metodológicas no início do século $\mathrm{XX}$, quando conviveu com os trobriandeses, em Papua, Nova Guiné, no Pacífico Ocidental, e ressaltava que "textos servem como documentos que incorporam as ideias nativas sem qualquer elemento estranho" (p. 331) - e destacava a importância

6 Optamos por utilizar as CMs para preservarmos a identidade dos participantes da pesquisa, uma vez que elas só assumem significado quando são combinadas aos demais parâmetros das Línguas de Sinais, respeitando, assim, a responsabilidade ética da pesquisa qualitativa.

7 No momento em que estávamos em campo, foram apontados três surdos líderes, entretanto, na etapa do processo metodológico, em que estávamos realizando as entrevistas, conseguimos realizálas apenas com dois desses surdos, pois o outro não se encontrava no município. 
de compreender a emissão de uma palavra dentro do texto em que foi produzida e de entender todo o texto em seu contexto de produção. Acreditamos que, para compreender a interação em Língua de Sinais, é preciso entender o contexto social e cultural em que a fala-em-interação é enunciada. Portanto, a observação participante é um método de pesquisa útil aos pesquisadores que visam compreender a conversa cotidiana através de uma ótica cultural.

Malinowski (1978) contribuiu em grande medida para o desenvolvimento e a consolidação da pesquisa etnográfica, pois, antes dele, havia uma separação entre o pesquisador de campo e o etnógrafo: enquanto um ficava responsável pela coleta de dados, cabia ao outro fazer as análises e tecer as reflexões teóricas. Foi Malinowski quem uniu os dois ofícios, demonstrando que era possível unir a pesquisa de campo ao saber teórico, sendo possível ao etnógrafo observar e analisar o comportamento de determinada população. $\mathrm{O}$ autor cunhou aspectos importantes para a pesquisa, como a observação participante, como recurso metodológico; o caderno de notas, como instrumento de coleta de dados, e o diário de campo, utilizado para a análise de dados. As pesquisas linguísticas feitas por esse antropólogo eram documentadas e analisadas através desse método.

Malinowski (1978) propôs uma metodologia capaz de investigar "todos" os aspectos de um grupo, e, embora pesquisas contemporâneas tenham mostrado essa inviabilidade, não podemos negar a sua contribuição ao campo das pesquisas sociais. Essa contribuição foi fundamental para a Antropologia e é utilizada por antropólogos linguistas que visam compreender a língua em seu contexto de produção. Como ressalta Duranti (1997, p. 96, tradução nossa): "antropólogos linguistas adotam o método etnográfico para concentrar os meios pelos quais a comunicação linguística é uma parte integral da cultura dos grupos estudados por eles" $\left.{ }^{\prime \prime}\right)$.

Assim, a partir de Malinowski (1978) e Duranti (1997), podemos perceber que é possível pesquisar os aspectos linguísticos de determinado grupo, por meio da observação e compreensão dos aspectos culturais deste. Se, de acordo com Malinowski (1978), uma palavra está para o texto, assim como este está para o contexto social, só conseguimos compreender determinado gênero se entendermos como está vinculado a determinada instituição social. Com base nessas observações, procuramos investigar o comportamento social e cultural dos Surdos de uma cidade da Zona da Mata Mineira, a fim de compreender como essas experiências estavam relacionadas com a Língua de Sinais, tendo, como foco específico, o processo de nomeação, que é uma característica particular dessa cultura.

8 Linguistic anthropologists adopt ethnographic methods to concentrate on the ways in which linguistic communication is an integral part of the groups they study. 
O percurso metodológico foi realizado da seguinte forma: primeiro, mapeamos quem eram os Surdos responsáveis pela nomeação através de entrevistas com Surdos e intérpretes do local e categorizados como Surdos líderes. Concluída essa etapa, partimos para o segundo percurso metodológico, que envolveu o acompanhamento dos Surdos nas atividades diárias, como ir à casa dos Surdos, acompanhá-los nas suas atividades diárias e em movimentos religiosos. A partir das entrevistas e das observações, bem como da catalogação dos sinais próprios dos Surdos - realizada no decorrer da inserção em campo -, triangulamos os dados para tecermos as análises acerca do processo de nomeação dos Surdos na cidade.

Os Surdos que consideramos líderes e que apareceram nas três entrevistas foram: Messe modo, a segunda etapa do campo envolveu esses sujeitos - apontados nas entrevistas com os ouvintes como os "Surdos que conhecem muita gente" e que "gostam de ensinar a LIBRAS" e classificados como Surdos chaves ou alfas da rede social. Essa etapa da pesquisa foi constituída por entrevistas semiestruturadas com os Surdos, e com roteiros personalizados para cada um dos Surdos Alfas, como indicado no quadro abaixo:

Quadro 1: Entrevistas com os Surdos Alfas

\begin{tabular}{|l|l|l|}
\hline $\begin{array}{l}\text { Questões: } \\
\text { 1) QUAL-PRIMEIRO-CONTATO- }\end{array}$ & $\begin{array}{l}\text { Recursos Utilizados: } \\
\text { - Filmadora } \\
\text { LIBRAS? }\end{array}$ & $\begin{array}{l}\text { Local da entrevista: } \\
\text { - Copa da casa do Surdo } \\
\text { 2) COMO-VOCE-DAR-SINAL-PESSOA? } \\
\text { 3) PODE-SINAL-PESSOA-TER-LETRA- } \\
\text { PORTUGUÊS? }\end{array}$ \\
$\begin{array}{l}\text { 4) PODE-TRANSFORMAR-SINAL? } \\
\text { PODE-TIRAR-LETRA-PORTUGUÊS? }\end{array}$ & \\
$\begin{array}{l}\text { 5) QUAL-SINAL-SURDO-VOCÊ- } \\
\text { CONHECE? }\end{array}$ & \\
\hline $\begin{array}{l}\text { Questões: } \\
\text { Observação: Essa entrevista não foi realizada } \\
\text { por motivos de afastamento da pessoa da } \\
\text { cidade de Viçosa, por motivos de saúde. }\end{array}$ & Recursos Utilizados: & Local da entrevista: \\
\hline
\end{tabular}




\begin{tabular}{|l|l|l|}
\hline \multicolumn{2}{|l|}{ Surdo } \\
\hline Questões: & Recursos Utilizados: & Local da entrevista: \\
1) SEU-SINAL? & - Filmadora & - Sala DLA, UFV \\
2) POR-QUE-SEU-SINAL? QUEM- & - Caderno de notas & \\
DEU-SINAL? & & \\
3) ONDE-VOCÊ- APRENDER - LIBRAS? & & \\
COMO-VOCÊ- APRENDER-LIBRAS? & & \\
4) VOCÊ-CONHECER-MINISTÉRIO- & & \\
SURDOS? QUAL- SUA-OPINIÂO? & & \\
5) ONDE-ENCONTRAR-SURDOS- & & \\
VIÇOSA? & & \\
\hline
\end{tabular}

As entrevistas com os Surdos líderes possibilitaram analisar os Sinais próprios e perceber as modificações linguísticas de cada um deles. Posteriormente a essa etapa, os sinais mapeados na pesquisa de campo foram separados e categorizados de acordo com a sua formação fonológica.

Para auxiliar no processo de investigação etnográfica, a câmera filmadora foi

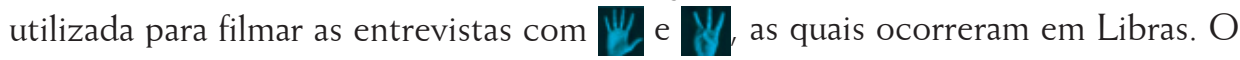
uso de imagens foi essencial para o entendimento das narrativas e das principais noções estabelecidas pelos Surdos líderes para a elaboração de um sinal próprio. Loder (2008) ressalta que, em registros com o uso de vídeo-áudio, é possível captar a gestualidade das pessoas, como e para onde olham no momento interacional. Expressões faciais e corporais, o olhar e a gestualidade são aspectos essenciais para se compreender a interação em Língua de Sinais, de acordo com a modalidade visual espacial dessa língua.

Duranti (1997) disserta acerca do uso de câmeras no trabalho de campo, e um dos aspectos mencionados para a rejeição do uso de filmagens é a possibilidade de interferir no meio investigado, mas a pesquisa social não é neutra, visto que a própria presença do pesquisador com o caderno de notas interfere na dinâmica do grupo. Desse modo, o uso da câmera é uma opção adotada pelo pesquisadorque auxilia na descrição minuciosa de eventos sociais, pois captura situações que são, muitas vezes, imperceptíveis pelos olhos humanos e sua interferência não é maior do que seria a de qualquer outro método na pesquisa social.

Entretanto, para a utilização desse recurso, é preciso conhecer o grupo estudado, ver a viabilidade do seu uso e adotar os procedimentos éticos da pesquisa qualitativa. Logo, antes de realizarmos as filmagens, esclarecemos que os vídeos seriam utilizados apenas pelos pesquisadores envolvidos e não exporiam nenhum dos participantes. Desse modo, antes de filmarmos, o Termo de Consentimento 
Livre e Esclarecido (TCLE) foi adotado e assinado por todos os sujeitos envolvidos. A seguir, discorreremos acerca das especificidades no processo de nomeação.

\section{ESPECIFICIDADES NO PROCESSO DE NOMEAÇÃO}

Para analisarmos o processo de nomeação a partir dos líderes que elaboram os sinais, inicialmente descrevemos o que cada Surdo líder acredita ser o procedimento adequado para a nomeação das pessoas e como isso se associa com aspectos gramaticais dos sinais. Percebemos uma flexibilização fonológica nos sinais próprios das pessoas Surdas no contexto estudado. Por meio dessa correlação entre a Fonologia do sinal próprio e as observações participantes, notamos determinado padrão na composição dos sinais próprios das pessoas da região.

Posteriormente, mapeamos os sinais evidenciados durante o trabalho de campo, os quais foram criados pelos Surdos líderes, e pontuamos as principais comparações e padronizações evidenciadas. A partir dos sinais próprios, observamos a demarcação de gênero representada via parâmetro $M$, referente a uma especificação de gênero. Geralmente, os sinais femininos são realizados como $\mathrm{M}$ de cima para baixo, de forma refreada, fazendo referência ao cabelo.

Investigamos, ainda, dois fatores referentes aos sinais próprios. O primeiro foi a predominância do uso do parâmetro $\mathrm{CM}$ do alfabeto datilológico, referente à inicial do nome da pessoa em Língua Portuguesa, geralmente criado por um dos Surdos líderes. O segundo é a criação de sinais a partir do léxico das Línguas espaciais-visuais, classificadores e configurações de mãos. Tais evidências serão descritas e analisadas consecutivamente, nos tópicos que seguem.

\subsection{0 processo de nomeação como demarcador cultural: 0 entendimento dos Surdos líderes}

Os sinais próprios podem remeter tanto a características físicas quanto a características relacionadas ao comportamento. Para entender como se desenvolve o processo de nomeação, é preciso se considerar a percepção de cada sujeito empoderado frente aos demais, para realizar essa tarefa. Por isso, procuramos descrever o modo como os Surdos líderes compreendem a ação de nomear, como o fazem e qual o significado dessa ação para eles.

O processo de nomeação confere uma identidade sociocultural à pessoa Surda, que (re)afirma e demarca uma localização desta no campo discursivo. De acordo com 
Heredia (2007), um sinal é uma forma de distinguir a pessoa na cultura surda, pois a forma do sinal fará referência a uma especificidade do sujeito. Assim, trata-se de um atributo particular da pessoa, o qual é representado através do sinal próprio.

O processo de nomeação na Libras ocorre a partir da percepção que um Surdo tem em relação a outro. Isso pode ser evidenciado em um dos relatos dos Surdos que nomeiam quando descrevem esse processo. W sinaliza que qualquer Surdo poderia dar o sinal. Porém é preciso olhar e conhecer a pessoa para lhe atribuir um sinal próprio, pois este deve combinar com o sujeito. Segundo a percepção de $M$ o processo de nomeação não é rápido, pode demorar em torno de seis meses para se chegar a um consenso sobre a criação de um sinal para uma pessoa, como afirmou $/$ em uma das conversas registradas em campo. Nesse momento, a pesquisadora perguntou-lhe, em LIBRAS, se era errado dar um sinal com a CM, fazendo referência à primeira letra do nome em português. $/ /$ respondeu que não era errado, no entanto, ele não fazia isso, pois considerava que era necessário um tempo maior de convivência com os Surdos para que pudesse observar a pessoa e nomeá-la conforme as suas características. "Se alguém pede para eu dar um sinal, eu não vou dar um sinal não, vou olhar, olhar e depois dar o sinal" (Entrevista M. outubro 2013).

Tal exemplo remete à temporalidade estabelecida para acontecer o processo de nomeação. M/ compartilhou uma situação de nomeação que ocorreu durante um curso de Libras por ele ministrado. Desde os primeiros dias, as pessoas insistiam no pedido de criação de sinais próprios. No entanto, sua resposta era negativa, visto que não poderia nomear enquanto não tivesse conhecimento suficiente acerca da pessoa. Apenas ao final do curso, ele teve a possibilidade de nomear, visto que já havia observado e adquirido conhecimento suficiente para elaborar sinais de acordo com as características dos sujeitos.

Podemos perceber que $/$ estabelece dois critérios fundamentais para nomear uma pessoa, sendo necessária, primeiro, a vivência durante um certo período de tempo com alguém, para que ele perceba a característica marcante do sujeito. Denominamos esse primeiro critério percepção visual. Em segundo lugar, há a recusa em criar um sinal que faça referência ao nome próprio em português, ou seja, utilizando o $\mathrm{CM}$ em alfabeto datilológico, remetendo à letra inicial do nome da pessoa.

Percebemos, por meio das descrições de $\mathbb{W}$, que não se trata apenas de uma observação física momentânea, mas de um conjunto de fatores que podem ser notados com maior tempo de convivência, como, por exemplo, um trejeito da pessoa ao sorrir ou movimentar o cabelo. Ainda, frente às descrições de 
refletimos acerca da possibilidade de o processo de nomeação se vincular ao ensino e aprendizagem da Libras. Ou seja, o tempo despendido para nomeação pode reunir aspectos significativos para a percepção visual da pessoa e, também, para o seu engajamento no uso da Língua de Sinais, o que dará sentido ao conferir um sinal próprio a uma pessoa.

A partir da descrição etnográfica, comparamos nossas percepções ao estudo de Heredía (2007), pois compreendemos a existência de um ritual de nomeação e a sua relação com as características físicas, sociais e culturais das pessoas. De acordo com a autora:

O sinal geralmente se refere a uma qualidade física, ou recursos que estão "à vista", como usa a roupa ou o penteado. Outra opção é a referência a um tipo de trabalho realizado pela pessoa "batizada". Embora esta alternativa seja mais comum para os nomes colocados nos ouvintes. Seria como dizer "advogado", "publicitário", "jornalista", especialmente quando se é uma pessoa que acaba de ser conhecida. Já se essa é uma pessoa que é muitas vezes vista ou fala-se sobre ela todos os dias, mesmo que seja ouvinte, será nomeada por um sinal específico que não se repete (HEREDIA, 2007, p.8, tradução nossa). ${ }^{9}$

Através da colocação de Heredía (2007), vemos que as características sociais e os papéis desempenhados pelas pessoas em um determinado contexto podem ser expressos através da criação de sinais próprios.

Tomando como referência o processo de elaboração de nomes próprios realizado por W'/2, sua perspectiva de nomeação alia-se a um incentivo pedagógico. Nesse sentido, (') identifica que, uma vez nomeada, a pessoa passa a ter mais referência com a língua e, desse modo, maior comprometimento com o aprendizado e com o uso de sinais no cotidiano.

Ao considerarmos a análise de Nonaka (2004) para além das contribuições gramaticais que envolvem as Línguas de Sinais, vemos a importância de atentarmos para os conhecimentos atrelados ao status linguístico conferido à língua, o qual é construído socialmente. Nesse sentido, elucidamos a relação do processo de ensino da língua como um fator relacionado à nomeação em Libras no contexto pesquisado.

Observamos também que, em ambos os casos, M e [it// elaboram sinais próprios para pessoas Surdas e pessoas ouvintes que estão em processo de aprendizagem da Libras. Identificamos, ainda, como uma das principais

9 Esta seña refiere por lo general a una cualidad física, o a rasgos que están "a la vista" como usos en la vestimenta o el peinado. Otra opción es la referencia a un tipo de trabajo que desempeña la persona "bautizada". Aunque esta alternativa es más frecuente para el apodo que se pone a los oyentes. Sería como decir "el abogado", "la publicista", "el periodista". Sobre todo cuando es una persona que se ve eventualmente, ya que si se trata de una persona que es vista frecuentemente o se habla de ella cotidianamente, aunque sea oyente, se buscará que sea nominada con una seña específica y no repetida (HEREDIA, 2007, p.8). 
características da nomeação realizada por (1'/), a utilização da CM vinculada à inicial do nome da pessoa em Língua Portuguesa, por meio do alfabeto datilológico em Libras.

Em uma das conversas sobre o uso da datilologia nos sinais próprios, M nos trouxe uma explicação embasada em uma palestra a que assistiu, com um professor de Linguística da Universidade de São Paulo (USP), durante a participação em um simpósio. W nos contou que antes era comum o uso da datilologia nos sinais próprios dos Surdos, mas, com o passar dos anos e as descobertas linguísticas da Libras, isso foi mudando.

Sua argumentação estava embasada na afirmação de que a Libras é uma língua diferente do Português. W destaca que o sinal próprio com a CM formada pela datilologia demarcava a influência do Português na Libras. De acordo com M, antigamente, quando os Surdos não tinham conhecimento acerca da gramática da Libras e da nomenclatura a ser utilizada para nomear, era normal a datilologia nos sinais próprios. No entanto, esse procedimento foi modificado, tendo em vista os estudos e a compreensão das pessoas Surdas a respeito do processo de nomeação.

Enquanto (WI) faz uso da datilologia na formação dos sinais próprios, IV acredita que a $\mathrm{CM}$ do sinal deve ser arbitrária em relação ao nome próprio em Português, como um modo de demarcar a autonomia linguística da Libras. Já quando faz a nominação, ele cria o sinal a partir de uma característica física da pessoa, utilizando tanto a datilologia quanto a CM pertencente ao léxico nativo da Libras. Embora utilize a CM do alfabeto datilológico para a formação dos sinais próprios, estes não se relacionam com os nomes das pessoas em português. Nesse ponto, coaduna-se com o posicionamento de $\mathbb{W}$, que acredita que o sinal próprio não deve ter correlação com o nome em português.

Assim, podemos associar a iconicidade dos sinais com a Fonologia e os aspectos culturais de um determinado grupo de sinalizantes. Pizzuto e Volterra (2000), Ortega e Morgan (2015) argumentam que a iconicidade de um sinal pode ser expressa através de um ou de mais parâmetros fonológicos das Línguas de Sinais, mas o modo como as pessoas compreendem o grau de iconicidade de determinado sinal varia de cultura para cultura, conforme o background cultural do sinalizante.

Posto isso, a fim de compreendermos os desdobramentos e como ocorrem as etapas do processo de nomeação, dividimo-los em três etapas, sendo estas: percepção dos indivíduos, interação social e atribuição de significado. Assim, nominar um sujeito envolve o modo como os Surdos líderes percebem aqueles que serão nomeados visual e socialmente. Além disso, é preciso um momento de convívio, que ocorre por meio da interação em Libras, para que depois lhes sejam atribuídos sinais próprios. 


\subsection{Os parâmetros gramaticais e as significações do contexto cultural}

Ao mapearmos os sinais próprios dos sujeitos Surdos, notamos que há variação na Fonologia dos sinais. Há distinções significativas relacionadas aos parâmetros gramaticais, principalmente no que se refere à $\mathrm{CM}$ e à L. Através do trabalho de campo, descrevemos 12 sinais, os quais foram estabelecidos pelos três líderes Surdos e possibilitam discorrer acerca da relação entre os aspectos fonológicos e a ligação com o contexto cultural em que os Surdos que nomeiam estão inseridos. Esses sinais estão descritos no quadro que segue:

Quadro 2: Constituição fonológica dos sinais próprios

\begin{tabular}{|c|c|c|c|}
\hline Surdo & Configuração de Mão & Locação & Movimento \\
\hline 1 & & Queixo & $\begin{array}{l}\text { Toque esquerda para direita contínuo e } \\
\text { repetido }\end{array}$ \\
\hline 2 & & Boca & $\begin{array}{l}\text { Aproximação movimentar os dedos de } \\
\text { forma contínua }\end{array}$ \\
\hline 3 & & Testa & $\begin{array}{l}\text { ontato de deslizamento da esquerda para a } \\
\text { direita refreado simples }\end{array}$ \\
\hline 4 & & Cabeça & $\begin{array}{l}\text { Aproximação Helicoloidal de cima para } \\
\text { baixo retenção simples }\end{array}$ \\
\hline 5 & & $\begin{array}{l}\text { Parte inferior dos } \\
\text { olhos }\end{array}$ & $\begin{array}{l}\text { Toque semicircular da esquerda para a } \\
\text { direita movimento refreado simples }\end{array}$ \\
\hline 6 & & Bochecha & $\begin{array}{l}\text { Toque de fora para dentro refreado } \\
\text { repetido } 2 \text { vezes }\end{array}$ \\
\hline 7 & & Bochecha & $\begin{array}{l}\text { Toque de fora para dentro repetido várias } \\
\text { vezes }\end{array}$ \\
\hline 8 & & Cabeça & $\begin{array}{l}\text { Aproximação Helicoloidal de cima para } \\
\text { baixo retenção simples }\end{array}$ \\
\hline 9 & & Cabeça & $\begin{array}{l}\text { Aproximação Helicoloidal de cima para } \\
\text { baixo retenção simples }\end{array}$ \\
\hline 10 & & Testa & $\begin{array}{l}\text { Contato de deslizamento da esquerda para } \\
\text { a direita fechando a mão começando pelo } \\
\text { dedo mínimo refreado simples }\end{array}$ \\
\hline 11 & & Garganta & $\begin{array}{l}\text { Garganta Toque deslizando de } \\
\text { dentro para fora movimento contínuo } \\
\text { repetido } 2 \text { vezes }\end{array}$ \\
\hline 12 & & Espaço Neutro & Cima para baixo refreado repetido 2 vezes \\
\hline
\end{tabular}


De acordo com esse quadro, é possível observar que os sinais 4, 8 e 9 possuem o mesmo $\mathrm{M}$ e fazem referência ao cabelo das mulheres, que categorizamos como uma característica física. Ressaltamos que esse padrão de movimento foi encontrado apenas nos sinais próprios das pessoas do sexo feminino. Ou seja, trata-se de uma marcação própria, aliada à norma fonológica do $\mathrm{M}$, como uma regra estabelecida $\mathrm{e}$ relacionada à noção de gênero. Além disso, entendemos que, nesse caso, os sinais 4,8 e 9 teriam a iconicidade expressa no $M$, uma vez que é esse parâmetro que faz alusão a essa característica física das pessoas do sexo feminino. Sendo assim, há duas questões significativas em relação a esses sinais: o padrão de gênero nos sinais próprios e a iconicidade encontrada no $\mathrm{M}$, que remete a uma característica física das mulheres.

Consideramos que os sinais 4,8 e 9 foram constituídos a partir de determinada percepção masculina acerca do que pode ser entendido como padrão social feminino. Esse significado é expresso por meio do parâmetro $M$, remetendo a Fonologia desses sinais próprios ao papel social de gênero. Logo, o contexto cultural dos sinais próprios também demonstra sua iconicidade, visto que não é possível fazer uma relação direta com seu significado. No entanto, vale ressaltar que, em um outro contexto ou até mesmo com o decorrer do tempo, os mesmos sinais poderiam ser considerados arbitrários, como salientado por Pizzuto e Volterra (2000) e Ortega e Morgan (2015).

Por meio da sociabilidade entre as pessoas Surdas, é possível realizar a observação e a criação de sinais próprios. Desse modo, o conceito de comunidade de fala de Gumperz \& Cook-Gumperz (1982) adequa-se à situação, visto que as pessoas criam sinais a partir de determinadas características culturais imbuídas no contexto, como, por exemplo, a constituição de gênero dos Surdos líderes. Assim, a constituição linguística aproxima-se do contexto do grupo e suas especificidades.

O mesmo processo de iconicidade fonológica ocorre, no caso dos sinais referentes às pessoas do sexo masculino, em relação ao parâmetro L. Os sinais 1, 3, 5 e 7 são significados a partir de uma característica física do corpo da pessoa, sendo ela marca de nascença, cova na bochecha ou no queixo, uma cicatriz ou um escurecimento ao redor dos olhos, geralmente na pálpebra inferior. Aqui, a iconicidade remete apenas às características físicas dos sujeitos e, diferentemente dos sinais das mulheres, não faz menção a nenhum papel social de gênero. A alusão a características físicas no rosto é demarcada, nesses casos, como sinal masculino.

Entendemos, então, que as marcações de gênero dos sinais próprios são significadas a partir de algum parâmetro da Fonologia da Libras e que o processo de formação desses sinais parte, em grande medida, da percepção de líderes Surdos. 
Levando-se em consideração as nomeações marcadas por meio das diferenças de gênero, enfatizamos que tais categorias, de acordo Avtar Brah (2006), não devem ser entendidas como essencialmente antagônicas, mas como delimitações históricas, compreendidas pelas práticas discursivas.

No que se refere ao parâmetro $\mathrm{CM}$, os sinais representados pelos números $4,5,7,8$ e 9 foram criados tendo como base a letra inicial do nome da pessoa em Língua Portuguesa, a partir do uso da datilologia em Libras. Podemos afirmar que, nos casos 5 e 7, por exemplo, as CM de e representam, consecutivamente, as letras R e T no alfabeto datilológico da Libras. Nessa situação, as CM poderiam ser consideradas como empréstimo linguístico da Língua Portuguesa, pois, de acordo com Faria-Nascimento (2009), o uso de algumas das CM na Libras conduzem a uma representação gráfica das letras do Português.

Ao mesmo tempo, ponderamos que o uso do alfabeto datilológico na Libras pode ser considerado um empréstimo linguístico da Língua Portuguesa e que, conforme descrito por Ferreira-Brito (1998), levando em consideração o léxico da Libras o empréstimo pode sofrer alterações em suas características fonológicas e morfológicas, como é possível perceber no caso desses sinais próprios.

Em relação a essas $\mathrm{CM}$, indicamos que, por um lado, há uma correlação entre o sinal próprio e sua identificação no meio de outros sinalizantes e, por outro, há uma aproximação entre o nome próprio em Português e a caracterização desse sujeito no meio ouvinte.

Além da questão do empréstimo linguístico, aludimos à influência do processo de aquisição e fluência da Libras nessa região, visto que muitos dos Surdos, incluindo alguns dos que têm o status de nomear em Língua de Sinais, possuem um histórico de aprendizagem da Língua de Sinais caseira ${ }^{10}$ em um primeiro momento da vida, para posterior acesso à Libras.

Embora, atualmente, os Surdos líderes sigam os conhecimentos linguísticos da Libras, há um aspecto cultural importante que diz respeito à impossibilidade de mudança do sinal. Ao questionarmos sobre a possibilidade de mudança de determinado nome próprio que tivesse em sua $\mathrm{CM}$ o uso das iniciais do nome em Língua Portuguesa, M respondeu-nos que o sinal não poderia ser mudado, uma vez que, quando a pessoa recebe o sinal, este não deve ser alterado. A nomeação envolve os sentimentos dos Surdos e, caso uma pessoa Surda tenha nomeado utilizando tais referências, a mudança do sinal afetaria os sentimentos daquele que o nomeou.

10 São considerados caseiros aqueles sinais desenvolvidos em ambiente familiar, sem maior contato com a Língua de Sinais padrão e com outros Surdos que participam de comunidades ou associações de Surdos (GEDIEL, 2010). 
Por último, percebemos que a CM dos sinais 1 e 3 foi criada de forma arbitrária em relação ao nome da pessoa em Português. Desse modo, fazem inferência direta a um aspecto físico, podendo ser considerados aqui um parâmetro icônico do sinal próprio. A CM do sinal próprio 2 faz referência à personalidade da pessoa, pelo fato de ela utilizar muitos classificadores ${ }^{11}$ ao se comunicar. Além disso, o uso de sons e movimentos orais para a comunicação com ouvintes, em específico, caracteriza a especificidade do sinal, de aproximação dos dedos de forma contínua, próxima à boca, que seria a $L$ do sinal. Assim, no que diz respeito à Fonologia do sinal próprio 2, podemos concluir que a CM e a L seriam arbitrárias.

Conforme descrevem Quadros e Karnopp (2004), os sinais não são necessariamente icônicos, ou seja, não utilizam uma representação mimética. Os sinais podem ser arbitrários, sendo atribuídos por meio do compartilhamento linguístico que se dá na interação social. Assim, nem sempre há uma correspondência icônica entre o sinal e o seu significado, tampouco são os sinais uma reprodução das palavras em português.

Notamos que, durante o processo de nomeação, a temporalidade para a criação de um sinal é modificada de acordo com a pessoa que cria o sinal. Além disso, verificamos o reconhecimento, entre os Surdos que nomeiam, de status e das maneiras específicas que cada um descreve como a "forma correta" de elaborar um sinal próprio. Isso envolve a percepção e o reconhecimento do outro como sinalizante e o uso ou não da datilologia referente ao nome em Português. Compreendemos que essas formas de percepção dos sujeitos acerca do processo de nominação estão diretamente relacionadas com a Fonologia dos sinais.

Os sinais que possuem CM remetendo à datilologia do nome em Português foram nominados por Surdos que não veem o uso da datilologia como um problema e o período de convivência para nomeação não precisa necessariamente ser extenso. Os sinais próprios seriam um incentivo à continuidade da aprendizagem da Libras. Já a nomeação de sinais com a CM arbitrária à datilologia do nome próprio em Português, a L e o M enfatizando uma característica física ou comportamental, condizem com um período longo de convivência entre pessoas sinalizantes para a obtenção de informações suficientes. E, posteriormente a esse período de convívio,

11 Neste trabalho, seguimos a perspectiva de classificadores adotada por Bernardino (2012). Para definir os classificadores na Libras, a autora se vale da definição de Supalla (1986), conhecida na literatura das Línguas de Sinais. Os classificadores, de acordo com Supalla (1986 apud Bernardino, 2012), são morfemas incorporados aos verbos de movimento (VM) e verbos de localização (VL), expressos através das mãos e do corpo para se referirem a um referente ou a um agente da ação. Os classificadores são uma representação icônica, performada por meio do corpo, e não são universais. A forma como são constituídos varia de cultura para cultura. 
é elaborado o sinal próprio. Nesse caso, os Surdos que nomeiam evitam criar sinais com base no nome próprio em Português, a fim de demarcarem a autonomia da Língua de Sinais em relação às línguas de modalidades orais auditivas, como no caso elucidado por

\section{CONSIDERAÇÕES FINAIS}

No decorrer do artigo, procuramos dissertar acerca do processo de nomeação dos Surdos sinalizantes de uma cidade da Zona da Mata Mineira. Ao entendermos esses Surdos como uma comunidade de fala, procuramos compreender a relação entre a iconicidade do sinal próprio e o contexto sociocultural. Desse modo, foi necessário verificar qual a percepção dos Surdos nominadores para podermos entender de que maneira a Fonologia dos sinais próprios se relaciona com o background cultural desses sujeitos.

Compreendemos o processo de nomeação com um aspecto cultural das Línguas de Sinais, um fenômeno presente na maioria das línguas sinalizadas, mas que possui significações diferentes de acordo com a cultura. Essa relativização é perceptível não apenas no significado socialmente atribuído, mas também na forma dos sinais. Assim, no campo investigado, os sinais próprios remetem à construção identitária dos sujeitos Surdos. Verificamos que a nomeação é desempenhada por meio de três etapas, sendo estas: percepção dos indivíduos, interação social e atribuição de significado. Observamos que, quando a convivência é maior entre o sujeito a ser nominado e o Surdo líder, é pouco frequente o uso da datilologia do nome em Português na Morfologia do sinal próprio. Geralmente, os parâmetros CM, L e M fazem referência a uma característica física ou comportamental da pessoa.

Ressaltamos também a diferença entre os sinais demarcadores das pessoas do sexo feminino e do sexo masculino. Nessa cidade da Zona da Mata Mineira, é recorrente o fato de os sinais próprios das pessoas do sexo feminino terem o L e o $\mathrm{M}$ do sinal próprio referindo-se ao cabelo; a iconicidade, nesses casos, refere-se aos papéis sociais de gênero. Assim, o gênero dos sinais próprios dessa comunidade de fala é reconhecível por esse parâmetro fonológico, diferente dos sinais masculinos, em que não foram encontrados padrões que se relacionam com os papéis sociais A iconicidade dos sinais masculinos é marcada pela referência a uma característica física, que pode ser expressa na CM, L e/ou M. 
Quando apresentamos os sinais catalogados, estamos também descrevendo as vivências e experiências dos Surdos líderes, pois são eles que possuem o status linguístico e o reconhecimento social para desempenhar tal ação. Assim, o processo de formação dos sinais está diretamente relacionado com a experiência linguística desses sujeitos e com o modo como eles compreendem a língua e a cultura Surda. Por meio da pesquisa etnográfica, percebemos que esse background cultural dos Surdos líderes está diretamente relacionado com o significado cultural do sinal próprio e com a sua forma. Ou seja, dentre os Surdos líderes, há aquele que consideram que formar um sinal com a CM de mão a partir da datilologia é demarcar uma relação de poder da Língua Portuguesa sobre a Língua de Sinais, por isso, considera que a maneira mais adequada é utilizar uma CM do léxico da Libras. Em contraposição a essa postura, vimos que um dos Surdos líderes faz uso da datilologia na formação dos sinais próprios e não julga ser necessário conviver muito com a pessoa para lhe atribuir um sinal próprio.

Já o outro Surdo líder nomeia uma pessoa a partir de uma característica física, não utilizando o alfabeto datilológico, apenas $\mathrm{CM}$ pertencentes ao léxico da Libras. Ele não entra no mérito de empoderamento da Libras, mas nomeia as pessoas em razão de ter aprendido Libras ainda na infância e ter tido maior contato com outros Surdos, sendo a sua experiência linguística em Língua de Sinais maior do que a experiência com a Língua Portuguesa.

Compreendemos o processo de nomeação das pessoas Surdas como um importante elemento da cultura Surda local e entendemos os sinais próprios como um marcador identitário e cultural desses sujeitos, pois é a forma como eles se reconhecem e são reconhecidos pelos demais sinalizantes.

\section{REFERÊNCIAS BIBLIOGRÁFICAS}

BERNARDINO, Elidéa Lúcia Almeida. (2012). O uso de classificadores na Língua de Sinais brasileira. ReVEL, v. 10, n. 19.

BRAH, Avtar.(2006). Diferença, diversidade, diferenciação. Cadernos Pagu, n.26, Jan-Jun, pp.329-376.

CARVALHINHOS, Patricia de Jesus. (2007). As origens dos nomes das pessoas. Domínios da Linguagem. Revista Eletrônica de Linguística. Ano $1, \mathrm{n}^{\circ} 1$.

DURANTI, Alessandro. (1997). Linguistic Antbropology. New York, NY: Cambridge University Press.

DURANTI, Alessandro. (2001). Linguistic Antbropology: A reader. Oxford: Blackwell Publishing Ltd. 
FARIA-NASCIMENTO, Sandra Patrícia de. (2009). Representações lexicais da LSB: uma proposta lexicográfica. Tese (Doutorado em Linguística). Universidade de Brasília. Brasília: Instituto de Letras.

FERREIRA-BRITO, Lucinda. (1998). Língua Brasileira de Sinais - Libras. In: Ferreira-Brito, Lucinda et al. (Org.). Programa de capacitação de recursos bumanos do ensino fundamental. vol. III: Língua Brasileira de Sinais. Brasília: MEC/SEESP.

GEDIEL, Ana Luisa. (2010). Falar com as Mãos e Ouvir com os Olhos? A corporificação dos Sinais e os significados dos corpos para os Surdos de Porto Alegre. (Tese de Doutorado em Antropologia Social). Porto Alegre: UFRGS.

GESSER, Audrei. (2009). LIBRAS? : Que língua é essa? : crenças e preconceitos em torno da Língua de Sinais e da realidade surda. São Paulo: Parábola Editorial.

GUMPERZ, John. (1992). Convenções de Contextualização. In: RIBEIRO, Branca Telles. Sociolinguística Interacional. Porto Alegre: AGE.

GUMPERZ, John \& COOK-GUMPERZ, Jenny. Introduction: language and the communication of social identity. In: GUMPERZ, John. Language and Social Identity. Cambridge: Cambridge University Press, 1982.

HEREDIA, Fabiola. (2007). "Me di cuenta de que podía hablar con las manos...": las personas sordas y su encuentro con la Lengua de Señas y la comunidad sorda*. in: IX Congreso Argentino de Antropología Social "Fronteras de la Antropología".

LAPLANTINE, François. (2003). Aprender Antropologia. São Paulo: Brasiliense.

LODER, Letícia Ludwig. (2008). Noções fundamentais: A organização do reparo. In: Loder, Letícia Ludwig. Jung, Neiva Maria.(Orgs) Fala-em-interação social: Introdução à análise da conversa etnometodológica. Campinas, SP: Mercado de Letras.

MENEZES, V.; SILVA, M.M.; GOMES, I.F. (2009). Sessenta anos de Linguística Aplicada: de onde viemos e para onde vamos. In: PEREIRA, R.C.; ROCA, P. Linguística Aplicada: um caminho com diferentes acessos. São Paulo: Contextos.

MINAYO, Maria Cecília. (1994). Teoria, método e criatividade. Petrópolis: Vozes.

MALINOWSKI, Bronislaw. (1978). Argonautas do Pacífico Ocidental. Coleção os Pensadores. São Paulo: Abril.

NONAKA, Angela. (2004). The forgotten endangered languages: Lessons on the importance of remembering from Thailand's Ban Khor Sign Language. Language in Society, 33, pp. 737-767.

NONAKA, Angela. (2014). (Almost) everyone here spoke Ban Khor Sign Languaged Until they started using TSL: Language shift and endangerment of a Thai village sign language. Language \& Communication, 38, pp. 54-72, May.

NONAKA, Angela; MESH, Kate; SAGARA, Keiko. (2015). Signed Names in Japonese Sign Language: Linguistic and Cultural Analyses. Sign Language Studies, Vol 16, $\mathrm{n}^{\mathrm{O}} 1$, pp. 57-85.

QUADROS, Ronice Muller de \& KARNOPP, Lodenir. (2004). Lingua de Sinais Brasileira Estudos Linguísticos. Porto Alegre: Artmed. 
ORTEGA, Gerardo; MORGANC, Gary. (2015). Phonological Development in Hearing Learners of a Sign Language: The Influence of Phonological Parameters, Sign Complexity, and Iconicity. Language Learning 65:3, pp. 660-688, September.

PADDEN \& HUMPHRIES. (2006). Inside Deaf Culture. Cambridge, Massachusetts: Harvard University Press.

PIZZUTO, E., \& VOLTERRA, V. (2000). Iconicity and transparency in Sign Languages: Across-linguistic cross-cultural view. In: K. Emmorey \& H. L. Lane (Eds.). The signs of language revisited: An anthology to honor Ursula Bellugi and Edward Klima. Mahwah, NJ: Erlbaum.

SUPALLA, Ted. (1986) The classifier system in American Sign Language. In: CRAIG, Colette. (Ed.) Typological studies in language: noun classes and categorization. 7, pp. 181-214. Amsterdam, Philadelphia: John Benjamin Publishing Company.

TURNER, Victor. (1986). Anthropology of Experience. Illinois: Illinois Books Ed.

Recebido: 19/07/2016

Aceito: 06/03/2017 